\title{
The Simulation Research on the BLDC Stator Resistance Affected By The Temperature Increment
}

\author{
Tiejun Fu, Zhongliang Pan , Liangliang Yang \\ 1Department of vehicle Engineering, JiLin University, No.5988, Renmin Street,130022, Changchun, \\ Jilin province China \\ 2Department of vehicle Engineering, JiLin University, No.5988,Renmin Street, 130022, Changchun, \\ Jilin province China \\ 3Department of vehicle Engineering, JiLin University, No.5988,Renmin Street, 130022, Changchun, \\ Jilin province China
}

Keywords: BLDC; the stator resistance; the finite element

\begin{abstract}
This paper changed temperature conditions to simulate by finite element software. We can observe the simulation results of the BLDC (brushless director current motor) stator resistance. Then we applied formula to calculate the BLDC stator resistance. At last, measuring the stator resistance of different temperatures by high temperature box, we could contrast the above results. We got the conclusions that the simulation had the characters of more convenient, simple, accurate than the formula method.
\end{abstract}

\section{Introduction}

As the BLDC stator resistance is consisted of many circles of copper wire, the resistivity of copper wire will change linear within limited temperature. When the motor runs, the temperature of stator resistance will rise for the reason that a certain current is given to the stator resistance, so the stator resistance will get bigger. The change of the stator resistance influence the accuracy of the rotor flux estimation, then influence the speed control precision and stability of the system [1][2].To improve the quality of speed control system, we must get the actual value of the stator resistance which will change with the fluctuation of internal temperature. The BLDC stator resistance was considered as constant value to input no matter simulink analysis model or ansoft maxwell finite model[3], then the model will calculate induction voltage, current, torque and so on. As the input of the model, the change of BLDC stator resistance will affect the performance of motor [4].So if we want to establish a accurate model, we must give a research on the change of the stator resistance. Traditional formula has a little different from the actual value. Then we need a convenient, simple and accurate method to solve this problem. Namely this paper mentioned above, the simulation research, measure the BLDC stator resistance[5].

\section{The measure of the BLDC stator resistance by high temperature box}

We booked two of the same BLDC motors, then disassembled one and got its stator resistance, put the stator resistance into high temperature box. As the high temperature box can afford temperatures vary 20 degree to 210 degree[6][7], and then some general BLDC motors work at that area. This paper took vary 20 degree to 120 degree for example. From 20 degree to 60 degree, we made a measure every 10 degree. Then between 60 degree and 120 degree we measured every 20 degree. Kept a record of a different temperature measured by universal meter. Eventually, we got the relationship between the BLDC stator resistance and temperatures as followed Table 1: 
Table 1: the BLDC stator resistance measured by high temperature box

\begin{tabular}{|c|c|}
\hline temperature(degree) & stator resistance $(\mathrm{m} \Omega)$ \\
\hline 20 & 62.19 \\
\hline 30 & 64.84 \\
\hline 40 & 67.49 \\
\hline 50 & 70.22 \\
\hline 60 & 72.89 \\
\hline 80 & 78.06 \\
\hline 100 & 83.37 \\
\hline 120 & 88.91 \\
\hline
\end{tabular}

\section{The calculation of the BLDC stator resistance by the traditional formula}

For the reason that the resistivity of copper wire will change linear within limited temperature, still the most prevalent method to measure the stator resistance was the traditional formula [8]:

$R r 1=[1+\alpha(T 1-T 0)] R r 0$

T0 - the reference 20 degree

T1 - the goal temperature

$\mathrm{Rr} 0$ - the stator resistance of the reference temperature 20

Rr1 - the stator resistance of the corresponding T1 temperature

$\alpha$ - a quotient affected by the material of the stator resistance

After consulted the reference statistics, we can know that the quotient $\alpha=0.0052$ [9][10]. As the reference 20 degree measure in high temperature box was $62.19 \mathrm{~m} \Omega$, then we need to calculate the stator resistance of corresponding temperature as the comparison object. So we take the $62.19 \mathrm{~m} \Omega$ as the initial value. The results of calculation as followed Table 2:

Table 2: the BLDC stator resistance by the traditional formula

\begin{tabular}{|c|c|}
\hline temperature(degree) & stator resistance $(\mathrm{m} \Omega)$ \\
\hline 20 & 62.19 \\
\hline 30 & 65.42 \\
\hline 40 & 68.53 \\
\hline 50 & 71.89 \\
\hline 60 & 74.88 \\
\hline 80 & 81.59 \\
\hline 100 & 88.06 \\
\hline 120 & 94.53 \\
\hline
\end{tabular}




\section{The finite element simulation of the BLDC stator resistance}

When we set a simulation model in the finite element software, please input the parameters as Table 3. In addition, the parameters of the actual stator and rotor diameter, the width of the permanent magnet, rated voltage, rated speed, rated current and so on also should be acknowledged[11].Then modify the temperature of simulation in the election setup of the finite element software, and self-inspection to check whether the model is right. After the simulation, we can see the results of the stator resistance on Figure 1 the simulation result of 40 degree and Figure 2 the simulation result of 80 degree. The corresponding stator resistance of armature phase resistance $\mathrm{R} 1$ was the simulation results. On the next line was the reference temperature result of 20 degree, here we only list the results of 40 degree and 80 degree.

The parameter of the booked BLDC motor as followed Table 3:

Table 3: the booked BLDC motor

\begin{tabular}{|c|c|}
\hline name & reference value \\
\hline Rated voltage $(\mathrm{V})$ & 48 \\
\hline Rated power $(\mathrm{W})$ & 500 \\
\hline Rated current $(\mathrm{A})$ & 12 \\
\hline Rated speed $(\mathrm{rpm} / \mathrm{min})$ & 500 \\
\hline Rated torque $(\mathrm{N} \cdot \mathrm{m})$ & 10 \\
\hline
\end{tabular}

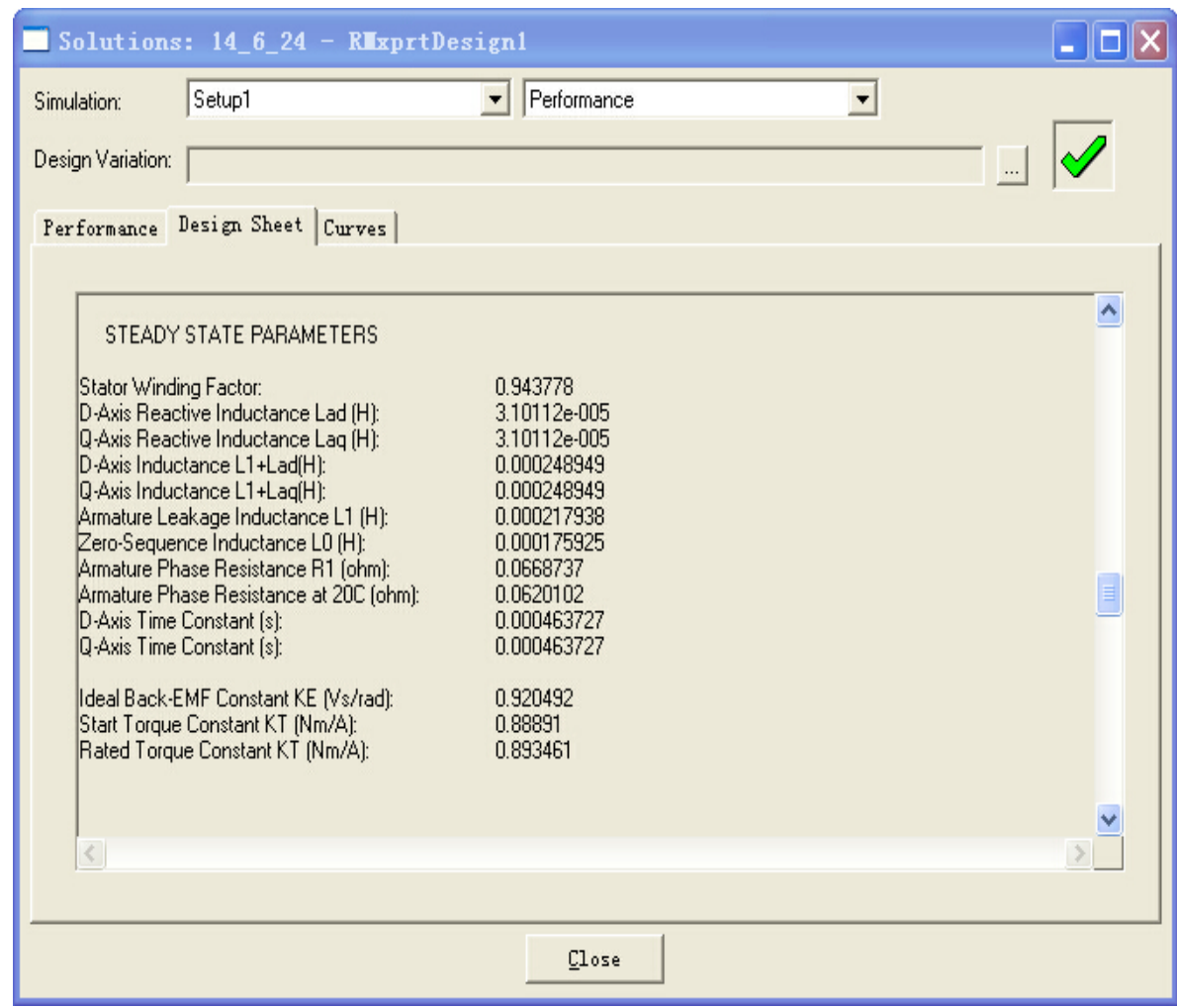

Fig.1: the simulation result of 40 degree 




Fig.2: $\quad$ the simulation result of 80 degree

For the reason that the actual stator resistance measured by high temperature box was considered as the comparison object, still we got the corresponding stator resistance by traditional formula. In order to make a comparison between the simulation and the value calculated by traditional formula, we input the same temperature as the mentioned in the formula. At last, we got a relationship between temperature and the stator resistance as followed Table 4:

Table 4: the BLDC stator resistance by simulation

\begin{tabular}{|c|c|}
\hline temperature (degree) & stator resistance $(\mathrm{m} \Omega)$ \\
\hline 20 & 62.01 \\
\hline 30 & 64.44 \\
\hline 40 & 66.87 \\
\hline 50 & 69.31 \\
\hline 60 & 71.74 \\
\hline 80 & 77.82 \\
\hline 100 & 82.92 \\
\hline 120 & 88.33 \\
\hline
\end{tabular}




\section{The comparison of the simulation results}



Fig.3: the comparison of the three measured results

Plotting the stator resistance measured by high temperature box, the stator resistance can be calculated by the traditional formula. The stator resistance calculated by the finite element software in a figure by software. According to the figure 3, we can clearly see that the trend of the stator resistance calculated by the finite element software is similar to the stator resistance measured by high temperature box. For the reason that the stator resistance can be calculated by the finite element software, also it was given the actual temperature and itself can really simulate [12]. While the traditional formula assumes that the resistivity of copper wire is a constant value which will not change with the fluctuation of temperature, that is why the finite element simulation is more accurate than the traditional formula.

\section{Conclusions}

As the BLDC stator resistance is consisted of many circles of copper wire, they were located inside the motor. If we want to measure the stator resistance, we have to disassemble the motor [13]. While the motor can not work without the stator resistance. Yet it is not accurate by the traditional formula, therefore, we introduce the finite element software method. This way has more advantages than the traditional formula, and has a profound influence on the measure of the stator resistance of different kinds of motors.

\section{References}

[1] Wang Lei, Deng Xianming, Zhang Xiao, Wang Kang. A novel parameter identification method for induction motor [J].IEEE,2010;265-268.

[2] Sayeed Mir,Malik E Elbuluk,Donald S Zinger.PI and Fuzzy Estimations for Tuning the Stator Resistance in DTC of Induction Machines. IEEE Trans. Power Electron,1998,13(2); 279 287

[3] H.B.Karrayaka. Induction machine parameter tracking from test data via pvm inveters[J]. IEEE,1997;227-233.

[4] sayeed mir,malik e elbuluk, donald s zinger. Pi and fuzzy estimations for turning the stator resistance in dtc of induction machines. IEEE trans. Power electron, 1998,13(2):279 287 
[5] P. H.Mellor, D. R. Turner. Real time prediction of temperatures in an

induction motor using microprocess or. Electric Machines and Power System. Num. 15.1988 pp. 3332352.

[6] R.L.Kotnik, An equivalent thermal circuit for nonventilated induction motors, AIEETrans, 1955,pp.1600.

[7]A.A.Abdel-Razek,J.L.Coulomb,M.Feliachi and J.C.Sabonnadiere.The Calculation of Electromagnetic Torque in Saturated Electric Machines within Combined Numerical and Anaytical Solutions of the Field Equations.IEEE Trans.on Magnetics,November 1981,Vol.Mag-17,NO.6.

[8] Hoang Le-Huy,Robert Perret,Rene Feuillet, Minimization of Torque Ripple in Brushless DC Motor Drives. IEEE TRANSACTIONSON IN DUSTRY APPLICATIONS,1986,22(4).

[9] C.Studer,A.Keyhani,T.Sebastian and S.K.Murthy.Study of Cogging Torque in Permanent Magnet Machines.IEEE IAS Annual Meeting New Orleans,Louisiana,USA,1997.

[10] Yoshihiro Murai,Yoshihiro Kawase,Kazuharu Ohashi,Kazuo Nagatake and Kyugo Okuyama. Torque Ripple Improvement for Brushless DC Miniature Motors. IEEE TRANSACTIONS ON INDUSTRY APPLICATIONS, 1989,25(3).

[11] Min Dai,Ali Keyhani and Tomy Sebastian. Torque Ripple Analysis of a PM Brushless DC Motor Using Finite Element Method. IEEE TRANSACTIONS ON ENERGY CONVERSION, 2004,19(1).

[12] Damir Zarko, Drago Ban and Thomas A. Lipo. Analytical Solution for Electromagnetic Torque in Surface Permanent-Magnet Motors Using Conformal Mapping. IEEE Trans, JULY 2009.VOL.45,NO.7.

[13] H.VuXuan, D. Lahaye, S.O. Ani, H. Polinder and J. A. Effect of Design Parameters on Electromagnetic Torque of PM Machines with Concentrated Windings using Nonlinear Dynamic FEM. IEEE International Electric Machines\& Drives Conference, 2011. 